\title{
Weighing Solutions to the Lottery Puzzle
}

ABSTRACT: The lottery puzzle can elicit strong intuitions in favour of skepticism, according to which we ordinary language-users speak falsely about knowledge with shocking regularity. Various contextualist and invariantist responses to the puzzle attempt to avoid this unwelcome result and preserve the competence of ordinary speakers. I will argue that these solutions can be successful only if they respect intuitions of a certain kind, and proceed to judge competing solutions by this criterion.

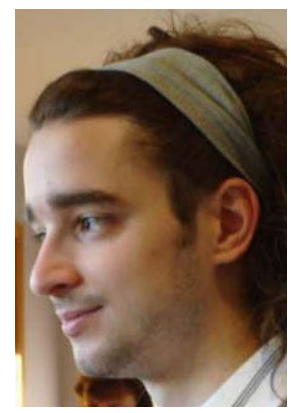

Mark Bowker is a final-year Philosophy student at the University of St Andrews, Scotland. His is interested primarily in issues in the philosophy of language particularly contextualism, relativism, and vagueness - and related areas in the philosophy of mind. He hopes to pursue these interests in postgraduate study.

1

The Puzzle

We normally take ourselves and others as knowing many and varied propositions. I know that I will graduate in June. I also know that if I will graduate in June, then I will not suffer a fatal and unexpected illness in the meantime. Considerations such as these give rise to the following puzzling argument, where $S$ is a subject, $\mathrm{O}$ is an ordinary proposition, and lottery proposition. ${ }^{1}$
1) $S$ knows that $O$

2) If $S$ knows that $O$, then $S$ knows that $L$

3) $S$ knows that $L^{2}$

O is a proposition that we would ordinarily take ourselves to know (e.g. the proposition that $S$ will graduate in June, or that S's car is parked outside) and whose truth entails the truth of L. However, while belief in L is both true and justified, we would not ordinarily take ourselves to know that L (e.g. that $S$ will not suffer a fatal and unexpected illness in the meantime, or that $S^{\prime}$ s car has not been stolen).

\footnotetext{
1. The lottery proposition is so-called because, in early versions of the puzzle, this role was played by the proposition that $S$ will not win the lottery. John Hawthorn, Knowledge and Lotteries (Oxford: Oxford University Press, 2003): 5.

2. Hawthorn, Knowledge and Lotteries: 2-3.
} 
The first premise is intuitively true. We do know such ordinary things as what people will be doing in a few months time and where their cars are parked. The second premise follows from S's knowledge that if $\mathrm{O}$ then $\mathrm{L}$, along with a closure principle such as the general principle that if $\mathrm{S}$ knows both that $\mathrm{P}$, and that if $\mathrm{P}$ then $Q$, then $S$ is at least in a position to infer, and therefore come to know, that Q. In some cases the inference from $\mathrm{P}$ to $\mathrm{Q}$ might be complicated enough that we doubt whether $S$ could actually perform it, but given the simple nature of the inference from $\mathrm{O}$ to $\mathrm{L}$, there seems nothing to stop $S$ from expanding their knowledge in this case.

Through apparently sound reasoning from seemingly acceptable premises, we arrive at the intuitively unacceptable conclusion that $S$ knows that L. The puzzle is interesting because it threatens to push us towards skepticism, thereby undermining our understanding of knowledge. $\mathrm{O}$ is, as stipulated, a proposition that we would ordinarily take ourselves to know, but if knowledge that $\mathrm{O}$ requires knowledge that $\mathrm{L}$, which we do not have, then surely we do not in fact have knowledge that $O$. If such skepticism is correct, then ordinary speakers make false judgments about what is known so regularly as to suggest that they lack competence with 'knows' as it appears in English.

We will consider in turn three broad epistemological theories - contextualism in section 2, interest-relative invariantism in section 3 , and traditional invariantism in section 4 - each of which resists the pressure toward skepticism in order to defend the ordinary speaker's competence with 'knows'. During comparison in section 5, I will argue that in order to defend our linguistic competence, certain intuitions must be accepted.

Given that only the traditional invariantist solution accepts these intuitions, it is preferable to the solutions of the contextualist or interestrelative invariantist. Although there is not space to do so here, contextualist, interestrelative invariantist, and traditional invariantist solutions to a variety of epistemological problems could be assessed along the same lines, ultimately allowing us to assess the theories themselves.

\section{Contextualism}

Contextualism is here a linguistic thesis about the meaning of 'knows' in English. The contextualist argues that 'knows' (like ' $\mathrm{I}$ ', 'here' and 'now') is context-sensitive in that its reference, and therefore the proposition expressed by a sentence containing it, varies depending on the context of its use.

Contextualism will be represented by David Lewis, both because there is not space here to spell out multiple contextualist theories and because Lewis introduces a framework that will be useful throughout our discussion. For Lewis, 'S knows that $\mathrm{P}$ ' is true in some context, just in case 'Ss evidence eliminates every not-P possibility' is also true in that context, where a not-P possibility is a possibility in which not-P obtains - a counter-possibility to the proposition that $\mathrm{P}$ - and is eliminated by S's evidence just in case the perceptual experience and memories that $S$ would have had were the possibility actual, are not the perceptual experience and 
memories that $S$ actually has. ${ }^{3}$ Through his definition, Lewis intends 'knows' to inherit the context-sensitivity of 'every'. ${ }^{4}$ In its quotidian uses 'every' refers not to all objects simpliciter, but to all objects within some restricted domain. If I direct the sentence "every glass is empty; time for my round," to the people at my table, what I have said does not entail that there are no full glasses anywhere in space and time, only that there are no full glasses anywhere on my table. ${ }^{5}$ We ignore the glasses behind the bar and those in other pubs and so on, and can do so legitimately; 'every glass' refers only to those glasses that we are not legitimately ignoring. Similarly, 'every not-P possibility' refers only to those not-P possibilities that are not legitimately ignored. ${ }^{6}$

The contextualist element in Lewis's theory is now revealed, for different not-P possibilities are legitimately ignored in different contexts. In a context $C$, in which the not-P possibility $S$ is being legitimately ignored, 'knows' may refer to a relation that is satisfied by anyone whose evidence eliminates the not-P possibilities $Q$ and $R$, while in another context $C^{*}$, which differs from C only in that $S$ is not being legitimately ignored, 'knows' refers to a relation that is satisfied only by those whose evidence eliminates $Q, R$ and $S .{ }^{7}$ Lewis offers various rules concerning what can and cannot be legitimately ignored, two of which in particular help us to further understand how context-sensitivity arises in his account.

The Rule of Belief states that we cannot properly ignore possibilities to which the subject gives, or ought to give, a sufficiently high degree of belief. What counts as a 'sufficiently high degree of belief' in a particular context depends on how much is at stake, i.e. on the possible consequences of a knowledge attribution in that context. ${ }^{8}$

When Cal tells me in the pub that he saw Joe pick a wallet up off the street, I may truly say 'Cal knows that Joe stole the wallet'. When sitting on Joe's jury, however, this sentence may no longer be truly asserted. In the relaxed context of the pub, we may legitimately ignore the possibility that Joe picked up the wallet in order to hand it in to the police, which Cal does not find likely in the slightest. In the strict context of a court, however, even such a low level of belief may be sufficient to bar us from legitimately ignoring this possibility. The Rule of Attention states that we do not properly ignore those possibilities that we are not actually ignoring. No matter how far-fetched and otherwise irrelevant a not-P possibility is, as long as we are attending to the possibility in a context, then it is not properly ignored in that context. ${ }^{9}$

A contextualist solution to the puzzle deems 1) is true, as $S^{\prime}$ s evidence eliminates all

3. Adapted from David Lewis, "Elusive Knowledge," Australasian Journal of Philosophy 74.4 (1996): 551. A contextualist definition should mention, rather than use, 'knows' so as to avoid reference to any specific relation.; Lewis, "Elusive Knowledge," 553.

4. Although the context-sensitivity of 'every' may not be as uncontroversial as Lewis makes out, we can grant it for the sake of illustration. Contextualism can be expressed without reliance on 'every'.

5. Of course I might say more than this. If my round includes our friends on another table, then 'every glass' might include theirs as well, but in that case we are still working with a restricted domain.

6. Lewis, "Elusive Knowledge," 553.

7. Ibid: 555 .

8. Ibid: 556

9. Ibid: 559 
possibilities inconsistent with $\mathrm{O}$, given that we are legitimately ignoring various far-fetched possibilities such as car thieves and unexpected illnesses. The second premise raises one of these far-fetched possibilities explicitly, which, by the Rule of Attention, can no longer be properly ignored. 'Knows' in 2) therefore expresses a different relation from that expressed by the same word in 1), a relation that holds between $\mathrm{S}$ and $\mathrm{O}$ only if $\mathrm{S}^{\prime}$ s evidence eliminates every possibility in which not-O obtains, including the possibility that not-L (e.g. that it is not the case that $S$ will not suffer a fatal and unexpected illness in the meantime).

In the context of 2), therefore, if ' $S$ knows that $\mathrm{O}^{\prime}$ is true, then $\mathrm{S}^{\prime} \mathrm{s}$ evidence eliminates every counter-possibility to the proposition that $\mathrm{L}$, in which case 'S knows that L' is also true. The conditional of 2) is therefore true. However, S's evidence does not eliminate the possibility that Not-L. As we cannot legitimately ignore this possibility, neither ' $\mathrm{S}$ knows that $\mathrm{O}$ ', nor ' $\mathrm{S}$ knows that $\mathrm{L}$ ', is true in this context. The counter-intuitive premise 3) is therefore false.

\section{Interest-Relative Invariantism}

Invariantism is the denial of contextualism, the linguistic thesis that 'knows' refers, in English, to the same relation in all contexts. Distinctive of interest-relative invariantism (IRI) is the thesis that whether or not a subject knows that $\mathrm{p}$ depends on "practical facts about the subject's environment."10 Facts about S, such as $\mathrm{S}^{\prime}$ 's evidence and beliefs, clearly determine whether or not $\mathrm{S}$ knows that $\mathrm{P}$, but the interestrelative invariantist adds to the list facts about
S's interests that are normally considered epistemically irrelevant, i.e. irrelevant to the question of whether or not $S$ satisfies the knowsrelation.

Different versions of IRI identify different facts about S's environment as epistemically relevant, but I will assume that the interestrelative invariantist may appeal to any of those facts about S's situation that the contextualist appeals to, such as the possibilities they are attending to and what is at stake in their context.

IRI can be framed in similar terms to contextualism: $\mathrm{S}$ knows that $\mathrm{P}$ just in case $\mathrm{S}$ 'S evidence eliminates every not-P possibility that is not legitimately ignored given $\mathrm{S}^{\prime}$ s practical situation. The domain restriction for 'every', which was contextually determined in Lewis's definition, is specified explicitly. In this definition 'knows' is not sensitive to features of context. Whether or not $\mathrm{S}$ knows that $\mathrm{P}$ does depend on the not-P possibilities that may legitimately be ignored, but these depend only on epistemically relevant facts about S's situation, not also on merely contextual facts.

How the interest-relative invariantist will respond to the puzzle depends on whether $S$ is attributor in addition to subject. Assume $S$ is going through the argument, making firstperson knowledge attributions. In this case, the interest-relative invariantist solves the puzzle similarly to the contextualist. 1) is true, given that $\mathrm{O}$ is of no particular importance to $\mathrm{S}^{\prime} \mathrm{S}$ practical interests, and that we may therefore legitimately ignore various counter-possibilities to $\mathrm{O}$, such as the possibility that not-L. As 2) raises $\mathrm{L}$ explicitly, not- $\mathrm{L}$ is no longer legitimately ignored. 2) is therefore true, for if $S$ knows that 
$\mathrm{O}, \mathrm{S}$ 's evidence eliminates the possibility that not-L, in which case $S$ also knows that L. 3), however, is false; $S$ 's evidence is consistent with the possibility that not- $\mathrm{L}$, and therefore $S$ knows neither that $\mathrm{O}$, nor that $\mathrm{L}$.

Now consider what is perhaps the most natural reading of the puzzle as formulated above-that on which $S$ is subject but not attributor. Unbeknownst to $S$, we are going through the argument, ascribing him or her knowledge in the third-person. As in the firstperson case, assuming that S's environment is such that we may legitimately ignore certain possibilities, 1) is true. Unlike the first-person case, however, S's situation is in no way affected when the attributor reaches premise 2). This suggests another solution to the puzzle. As $S$ knows that $\mathrm{O}$, his or her situation is such that the possibility that not-L can be legitimately ignored. If this is so, then S's evidence also eliminates every counter-possibility to $\mathrm{L}$ that cannot legitimately be ignored. S therefore knows that $\mathrm{L}$.

But if $\mathrm{S}$ knows that L, why does 3) strike us as absurd? Hawthorn explains that we are disposed to "overproject" our standards onto others, without considering those set by their practical situation. ${ }^{11}$ When we, the attributors, consider premise 2), our situation is such that we can neither ignore the possibility that not-L, nor know that L. Although $S$ remains unaffected by the change in our situation, we project our standards on to $S$, which blinds us to the truth of 3).

\section{Traditional Invariantism}

As said previously, invariantism, the denial of contextualism, is the linguistic thesis that the English word 'knows' expresses a single relation in all contexts of use. What I call traditional invariantism contrasts with interestrelative invariantism, its distinctive thesis being that whether or not $S$ knows that $P$ is in no part determined by facts about S's practical environment.

Harman and Sherman suggest an additional thesis through which the traditional invariantist can respond to the puzzle, namely that knowledge "can and usually does rest on assumptions one justifiably takes for granted without knowing them to be true."12 Harman and Sherman defend this thesis as an acceptable way to reconcile our judgements that, while we know ordinary propositions but not lottery propositions, the truth of the former rests on the truth of the latter. Typically we can only know ordinary propositions only by taking various lottery propositions for granted, but such assumption does not amount to full belief, let alone knowledge. ${ }^{13}$

The traditional invariantist can build Harman and Sherman's thesis in to their definition of knowledge, which can in turn be framed in Lewis's terms: $S$ knows that $P$ just in case $S^{\prime}$ 's evidence eliminates every not-P possibility whose negation $S$ does not justifiably take for granted. All invariantists allow that 'knows' expresses the same relation in all

11. Hawthorn, Knowledge and Lotteries, 163. Hawthorn says that we "overproject our own lack of knowledge" onto others. This fits the current case, but is inferior to the version in the body of the text, which applies also in cases where an attributor has very high standards but still knows that L. See Stanley, Knowledge and Practical Interests, 99-101.

12. Gilbert Harman and Brett Sherman, "Knowledge, Assumptions, Lotteries," Philosophical Issues 14 (2004): 492.

13. Ibid: 494. 
contexts of use, and that whether this relation holds is determined by facts about the subject, but our traditional invariantist includes facts about the subject's assumptions among these epistemically relevant facts.

Armed with Harman and Sherman's thesis, the traditional invariantist is ready to respond to the puzzle. 1) is true; $S$ knows that $\mathrm{O}$ but only because they are justifiably taking for granted that $\mathrm{L}$, not-L being a possibility inconsistent with $\mathrm{O}$ that $\mathrm{S}$ 's evidence does not eliminate. Because $\mathrm{L}$ is an assumption on which knowledge of $\mathrm{O}$ rests, 2) is false. The traditional invariantist must deny the closure principle from which 2) follows; that generally, if $S$ knows both that $P$ and that if $P$ then $Q$, then $S$ is in a position to know that $\mathrm{Q}$. The consequent may be a proposition that $S$ takes for granted in order to know the antecedent, and one cannot come to know the truth of a proposition simply by taking it for granted. ${ }^{14}$ The traditional invariantist need not, and should not, deny closure wholesale. One can often come to know that $Q$ from one's knowledge that $\mathrm{P}$ and that if $\mathrm{P}$ then $\mathrm{Q}$, but not in cases where $Q$ is assumed in order to know that $P$.

Hawthorn objects that "denial of closure interacts disastrously with the thesis that knowledge is the norm of assertion."15 Many find appeal in the principle that one is warranted in asserting that $\mathrm{P}$ at time $\mathrm{T}$, if and only if one knows that $\mathrm{P}$ at $\mathrm{T}$. Those who reject the unqualified closure principle but accept the knowledge norm of assertion will, in some cases, deem both $\mathrm{P}$ and if $\mathrm{P}$ then $\mathrm{Q}$ assertable, but $Q$ unassertable, which Hawthorn argues

can lead to odd conversations. For example:

$$
\begin{aligned}
& \text { Do you agree that you will graduate in June? } \\
& \text { - Yes } \\
& \text { Do you agree that if you will graduate in June, } \\
& \text { then you will not suffer a fatal and unexpected } \\
& \text { illness in the meantime? } \\
& \text { - Yes }
\end{aligned}
$$

Then surely you agree that you will not suffer a fatal and unexpected illness in the meantime?

- Absolutely not!

This is indeed a peculiar conversation but it is not one that the traditional invariantist can be forced into, even while accepting Harman and Sherman's thesis and operating under the knowledge norm of assertion, because a natural and legitimate answer to the final question is 'Yes'. To know that you will graduate in June, one must assume that you will not suffer a fatal and unexpected illness in the meantime. While this assumption is not itself known, and so, through the knowledge norm of assertion, cannot legitimately be asserted, it may still be legitimately agreed to. ${ }^{16}$

Making an outright, unpressured assertion implies that one has reason for the assertion beyond mere opinion. While this may also be true for some cases of agreement, in the case above, nothing suggests that one is being called upon for anything more than simple opinion, expressed either by agreement or disagreement. ${ }^{17}$ Without reason to think it false,

14. Ibid., 494

15. Hawthorn, Knowledge and Lotteries, 39.

16. Harman and Sherman, "Knowledge, Assumptions, Lotteries," 496-497.

17. A ranking Government official asked 'Do you agree with the rumors that world war will break out in two days?' should have more than opinion to support their agreement. This is due to their position of authority and the high stakes of the situation, both of which must be absent in the case above if it is to succeed as an objection to closure denial. 
and with nothing important hinging on its truth, there seems no reason to disagree with such a natural assumption.

Hawthorn might hope to construct a parallel case where our traditional invariantist asserts both that $\mathrm{P}$, and that if $\mathrm{P}$ then $\mathrm{Q}$, but refuses to assert that $\mathrm{Q}$. These hopes cannot be realized, however, because for any clearly unknown, and therefore unassertable consequent, the corresponding antecedent and conditional are not assertable in the same breath. When assertion that $\mathrm{Q}$ recommends to one's audience belief in a proposition that one does not know oneself, one cannot properly assert that Q. For the same reason $\mathrm{P}$ and if $\mathrm{P}$ then $\mathrm{Q}$ are unassertable together; in asserting both of these propositions, one equally recommends the unknown conclusion that $Q$ to one's audience.

\section{Comparison}

The contextualist and interest-relative invariantist solutions to the puzzle might claim superiority over that of the traditional invariantist solution on the grounds that both of the former accept the truth of 2), while the latter rejects 2) and the closure principle from which it follows. Hawthorn expresses concern about such "revisionary" proposals. ${ }^{18}$ This concern is one that I share.

Some constraint on rejected intuitions is needed, lest theories grow totally detached from practice, but we must be careful about the constraint that we impose. One clearly unsatisfactory constraint is that solutions to the puzzle must respect all pre-theoretical intuitions. ${ }^{19}$ The argument from 1) and 2) to 3) is puzzling precisely because it proceeds from intuitively acceptable premises and assumptions, by intuitively acceptable reasoning, to an intuitively unacceptable conclusion - something intuitive has to go, whether it is the closure principle required to motivate 2 ), the invariance of the 'knows' relation, or the falsity of 3).

Each solution aims to avoid skepticism and thereby maintain that ordinary speakers have a competence with 'knows' sufficient for making true and uncontroversial knowledge attributions and denials. A speaker may be said to possess this competence by virtue of having certain intuitions. For example, one whose intuitions consider a wide range of obviously true knowledge attributions false, for example, could only be judged to have an incomplete grasp of 'knows' as it is used in English. In order to respect the competence of ordinary speakers, therefore, solutions to the puzzle must respect those intuitions on which this competence depends.

I propose a rough constraint designed to preserve these intuitions while permitting the rejection of those that result from previous acceptance of theory or general philosophizing: solutions to the puzzle must be such that they make intuitively acceptable the rejection of any pre-theoretical intuitions rejected. Acceptance of philosophical theory does not instantly, if ever, destroy linguistic competence, as evidenced by the generally acceptable behavior of philosophers in ordinary conversation. Intuitions resulting from this competence are therefore secure enough to survive theorizing,

18. Hawthorn, Knowledge and Lotteries, 38.

19. I use 'pre-theoretical' to express a relative notion. What is pre-theoretical with respect to one theory may be posttheoretical with respect to another. I do not imply, therefore, that there are any absolutely pre-theoretical intuitions. 
while those easily destroyed by acceptance of epistemological theory are likely the result of previous theorizing.

Our traditional invariantist abides by this constraint, for once we accept that knowledge rests on assumptions (itself a highly intuitive thesis), the closure principle mentioned at the outset, which allows one to derive knowledge that $\mathrm{P}$ from the assumption that $\mathrm{P}$, clearly overgeneralizes. Its lack of resilience to theory indicates that this intuition itself comes from doing epistemology, and this is substantiated by the difficulty with which non-philosophers assent to it. ${ }^{20}$

The other solutions, however, fall afoul of our constraint. The contextualist rejects the intuition that 'knows' expresses an invariant relation, but, as Lewis demonstrates, contextualists often find themselves, both in conversation and in print, unable to avoid use/ mention fallacies, indicating that this intuition shows no sign of subsidence and stems from linguistic competence. ${ }^{21}$

IRI rejects our intuition that 3) is false in third-person cases. This pre-theoretical intuition is explained by the projection of our raised evidential standards onto S. Even after we accept our propensity to "overproject", however, 3) remains intuitively false. This intuition regarding the truth of a simple knowledge attribution very plausibly stems from our linguistic competence, and is therefore the kind of intuition that theory should respect.

Both contextualist and interest-relative invariantist solutions to the puzzle fail to satisfy the constraint on possible solutions outlined above, which in response to Hawthorn's worry, filters out overly revisionary theories and restricts the extent to which they may reject pre-theoretical intuitions- particularly those arising from our clear linguistic competence. One would have to assess their responses to a variety of problems in order to evaluate the theories themselves, but regarding this particular puzzle, as only the traditional invariantist solution can satisfy the important constraint above, it is superior to the solutions offered by the other two theories.

20. This is of course a hypothesis unconfirmed by rigorous experimentation, but non-philosophers who make no pretence are usually puzzled by the generality of the closure principle discussed in this essay (even once they understand the notation), finding individual instances of closure much more acceptable.

21. See Lewis, "Elusive Knowledge," 566. Lewis wants it to remain open which knowledge-relation is referred to when he talks about things "we used to know". In his own theory, however, Lewis refers to some particular relation, determined by the context of use. 